\title{
Not So Far Away
}

In Memory of Steve Larson

Freely $\quad \cdot=72$

Stephen Rodgers (2012)
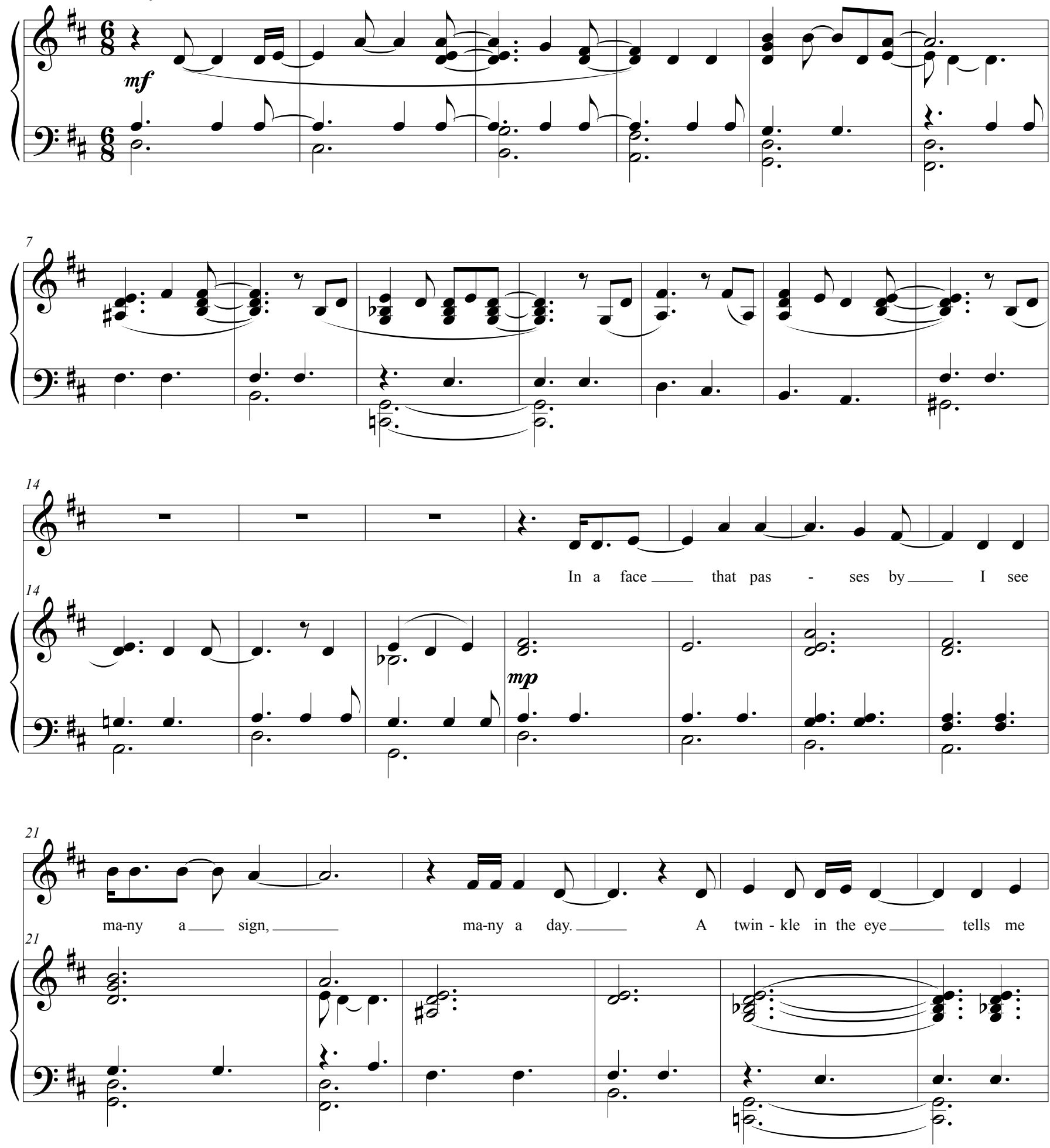
2

Not So Far Away
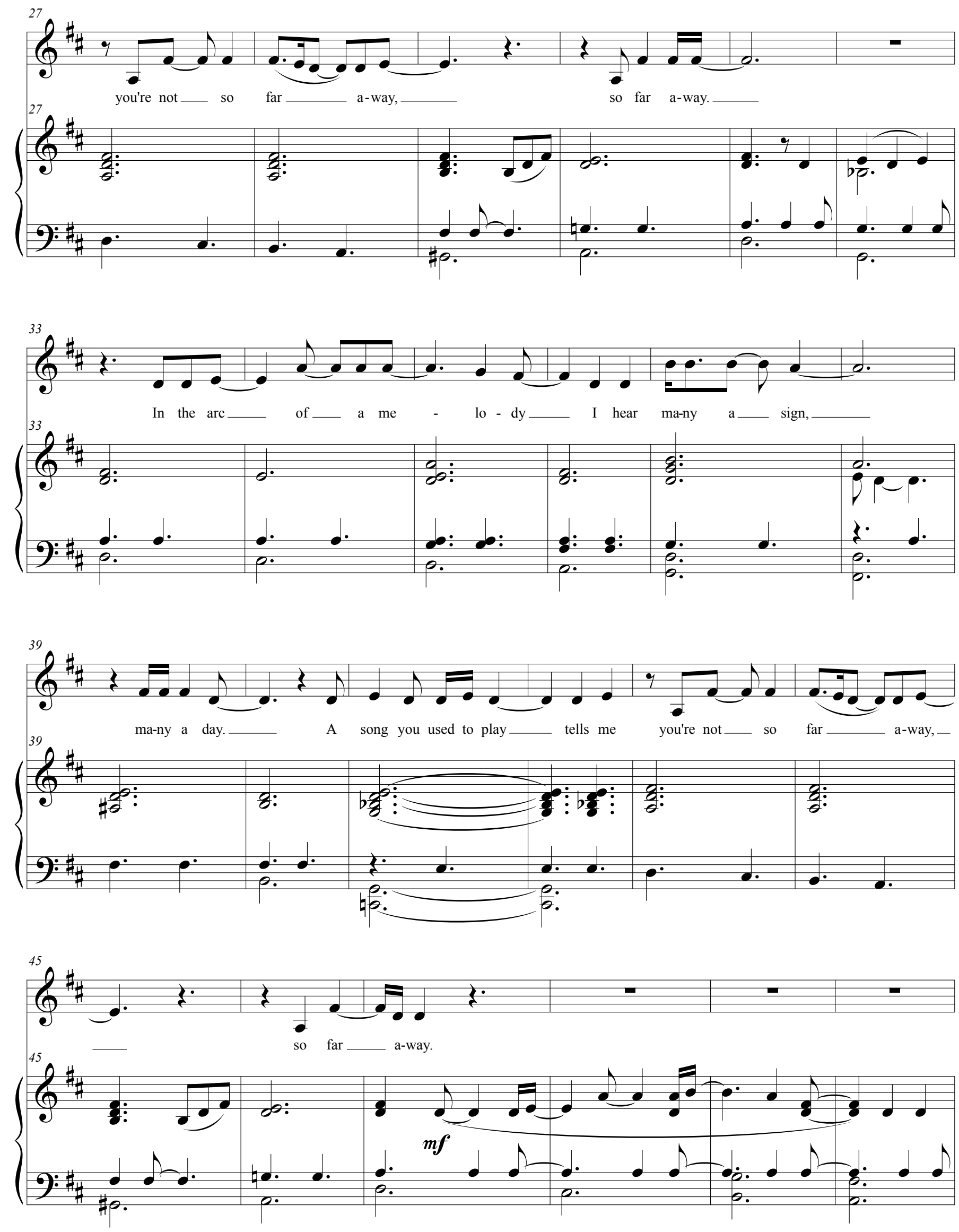

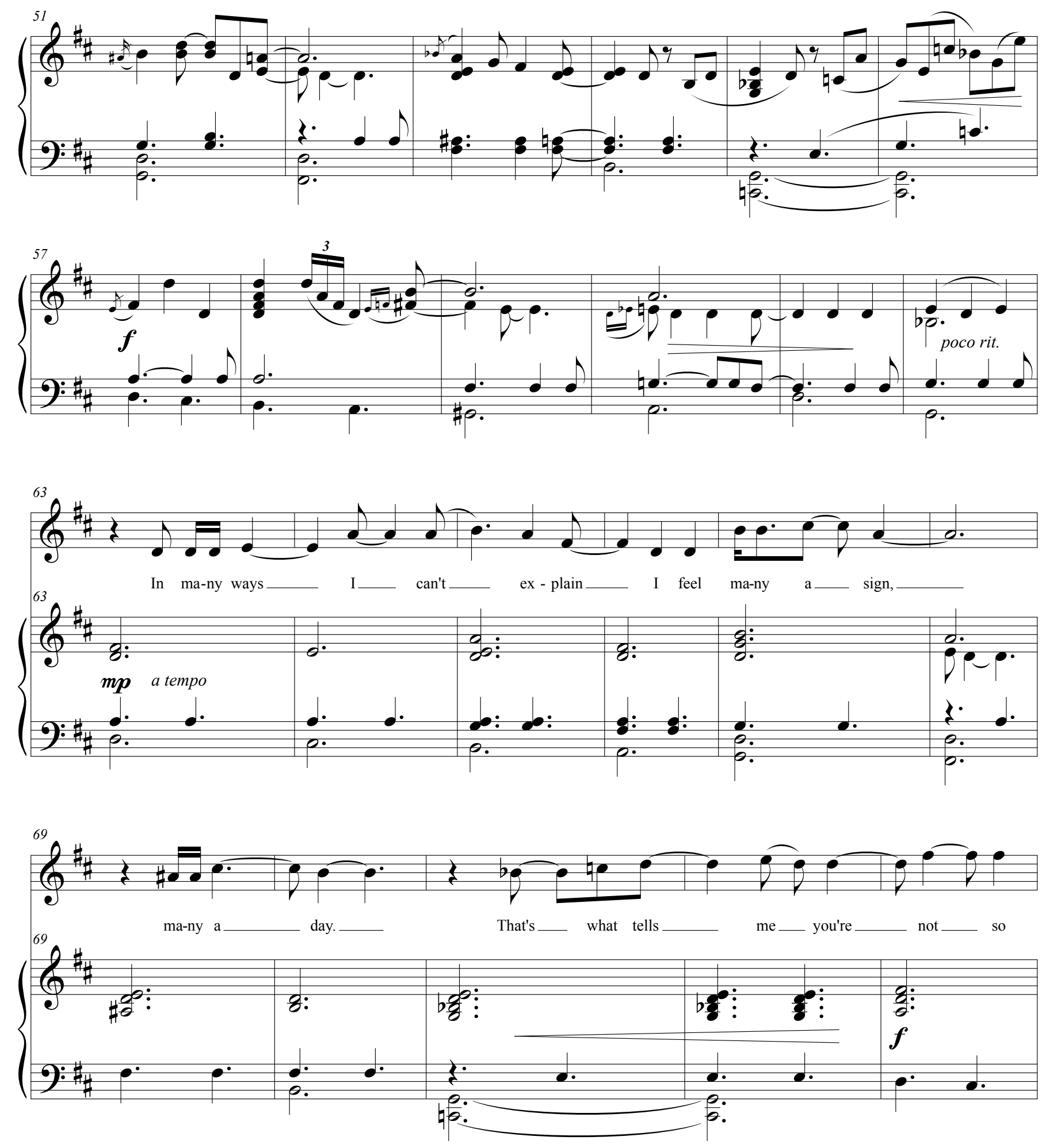
4

Not So Far Away
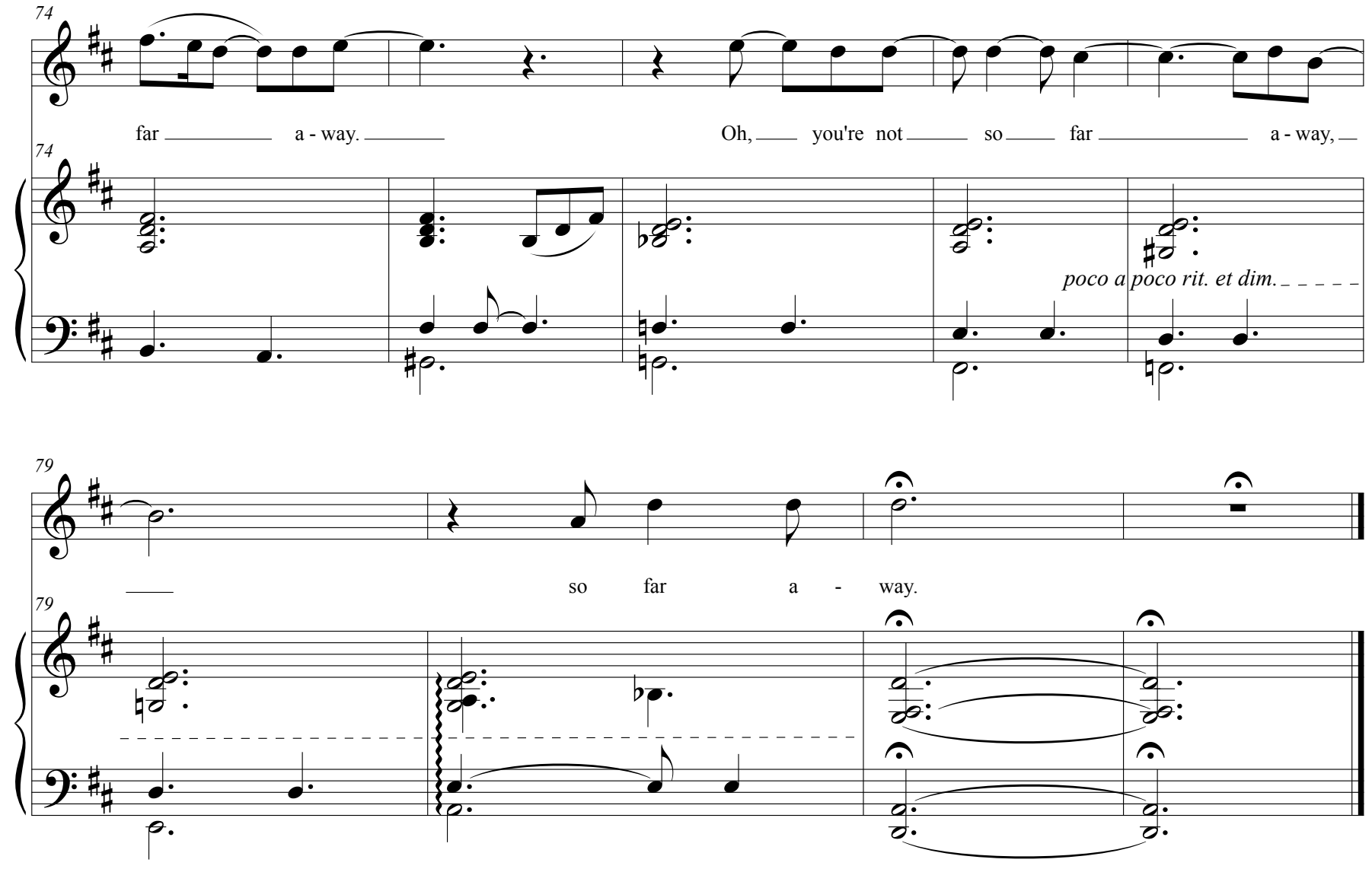